\title{
The changing information environment for nanotechnology: online audiences and content
}

\author{
Ashley A. Anderson • Dominique Brossard • \\ Dietram A. Scheufele
}

Received: 23 September 2009/Accepted: 19 January 2010/Published online: 7 February 2010

(C) Springer Science+Business Media B.V. 2010

\begin{abstract}
The shift toward online communication in all realms, from print newspapers to broadcast television, has implications for how the general public consumes information about nanotechnology. The goal of this study is threefold: to investigate who is using online sources for information and news about science and nanotechnology, to examine what the general public is searching for online with regards to nanotechnology, and to analyze what they find in online content of nanotechnology. Using survey data, we find those who report the Internet as their primary source of science and technology news are diverse in age, more knowledgeable about science and nanotechnology, highly educated, male, and more diverse racially than users of other media. In a comparison of demographic data on actual visits by online users to general news and science Web sites, science sites attracted more male, non-white users from the Western region of the United States than news sites did. News sites, on the other hand, attracted those with a slightly higher level of education. Our analysis of published estimates of keyword searches on
\end{abstract}

Electronic supplementary material The online version of this article (doi:10.1007/s11051-010-9860-2) contains supplementary material, which is available to authorized users.

A. A. Anderson $(\bowtie) \cdot D$. Brossard · D. A. Scheufele Department of Life Sciences Communication, University of Wisconsin-Madison, 1545 Observatory Dr., Madison, WI 53706, USA

e-mail: aaanderson3@wisc.edu nanotechnology reveals people are turning to the Internet to search for keyword searches related to the future, health, and applications of nanotechnology. A content analysis of online content reveals health content dominates overall. Comparisons of content in different types of sites-blogs, government, and general sites-are conducted.

Keywords Nanotechnology · Online content analysis · Online audiences · Information seeking · Online communication - Public perceptions . Societal implications

News audiences are increasingly turning to online sources for daily news and information, with $20 \%$ of all Americans turning to the Internet for most of their science news (Horrigan 2006). Online media differ from traditional news outlets on a number of dimensions. In this article, we examine two of these differences as they relate to how audiences learn and form attitudes about science and emerging technologies. First, online media allow users to seek for specific aspects of an issue, such as health-related information about nanotechnology, rather than having preselected content delivered to them through newspapers or television. Tellingly, the Internet is increasingly becoming a research tool for science issues, with approximately 7 in 10 Internet users going online to look up the meaning of a scientific concept or term or to look for an answer to a question 
about a scientific concept or theory (Horrigan 2006). At this point, however, we know very little about the strategies and search patterns that audiences use to find this information. Second, the online information environment includes user-generated content, such as blogs, or crowd-sourced content, such as Wikipedia that likely differs from traditional news outlets, both with respect to how issues are covered and the relative emphasis that is given to different issues.

Two recent media stories about nanotechnology highlight the importance of online media. Both were covered in traditional outlets, but created much more intense and immediate news waves online. One story was based on a study in the European Respiratory Journal (Song et al. 2009) and linked the deaths of Chinese factory workers to nanoparticle exposure in their workplace (Lyn 2009). The other reported on a study (Peng et al. 2009) about the ability of nanotechnology to detect lung cancer using a sensor that uses gold nanoparticles (Kelland 2009).

These studies are interesting from at least two perspectives. First, they highlight the complexity that lay audiences face when trying to make sense of emerging technologies. Within a few weeks, nanotechnology was both blamed for causing lung disease and hailed as technology that enables early-detection of lung cancer. These reports in traditional media may seem contradictory to some lay audiences and are therefore likely to increase interest in online sources that can provide additional background information. In fact, one study showed that $65 \%$ of online users have gone online to learn more about a scientific story or discovery they first learned about offline (Horrigan 2006). Second, the information environment that audiences encounter online is likely much richer than traditional offline media. The original Reuters story (Lyn 2009) about potential harmful effects of nanomaterials in China, for instance was roughly 500 words long. Many of the blog posts that disseminated the story online were significantly longer.

In spite of these changing information environments, researchers continue to know little about who uses the Internet for information about science and emerging technologies and about what they encounter in the online setting. Events that generate a lot of media coverage can draw public attention quickly to an issue and are likely to motivate information seeking through online sources, where information is typically available instantly. The past year has seen a dramatic increase in new media technologies. Use of social networking sites like Facebook and Twitter are on the rise. The percentage of Internet users who use Twitter nearly doubled in the last half of 2008 (Lenhart and Fox 2009). Print newspapers are on the decline and the online presence of newspapers is growing, with print newspaper readership down by $9 \%$ and online readership up by 5\% between 2006 and 2008 (Pew Research Center 2009). A growing number of people are turning to wireless technologies, with $56 \%$ of all Americans logging online via a personal digital assistant, laptop, mobile phone, or some other wireless device (Horrigan 2009). Researchers have begun to understand how the public uses online sources for news on science (Horrigan 2006), yet no research has explored what people find when they turn to the Internet for information on nanotechnology.

The research we present here identifies which members of the public are most likely to turn to online sources for scientific news in general and nanotechnology in particular, and the information they encounter while there. This study will provide empirical data on three related areas. First, we define basic demographics of people who use Internet for science and technology news based on survey and behavioral tracking data. Second, we explore the search terms used by people who search for nanotechnology online. Finally, we identify what kind of information people encounter when they come across the top-ranked nanotechnology sites in online searches. Uncovering the online information context for nanotechnology is absolutely critical for researchers and policymakers when they look to the Internet as the emerging medium of choice for information dissemination and develop new tools to communicate with the public. And while the Internet as a tool for public outreach and education about nanotechnology may be still in its infancy, it will likely increase dramatically in the next few years, given the disappearance of science news in traditional news outlets (Dudo et al. 2009).

\section{Science- and emerging technologies-related news online}

Researchers are beginning to understand how people consume science news and information in the online 
setting. For instance, and not surprisingly, those who primarily use online media, or "net-newsers," make up the category of the public most likely to obtain information about science and technology online (Pew Research Center 2008). More generally, it is clear that the public at large is increasingly turning to online sources for information about science (National Science Board 2004). The Internet comes second to just television as Americans' primary source for news on science, but those who have access to broadband at home are equally as likely to use it as they are to use television as a source for science information (Horrigan 2006). Furthermore, individuals tend to go to the Internet when they want more information about a scientific story they heard offline, and they would turn first to the Internet to look up answers to questions about scientific issues such as stem cell research, climate change, or origins of life on Earth (Horrigan 2006).

Given the increasing prevalence of online sources for information and particularly for science and technology information, researchers need a better understanding of who these online users are. We explore this through the following research questions:

RQ1: What are the demographic and knowledge patterns for different audience segments of media on science and technology?

RQ2: How are science Web site users different from news Web site users?

Following developing an understanding of who users are, we also examine how people search for nanotechnology. How people arrive at information online about a specific science topic such as nanotechnology is likely to be fueled by search engine usage, particularly if they have specific questions about the scientific topic. Nearly half of all Internet users use search engines in a typical day, second to just e-mail, which $60 \%$ of individuals use on a typical day, and ahead of checking news and weather online (Fallows 2008). Furthermore, when turning to the Internet for answers to questions about science, approximately 9 in 10 people will turn first to a search engine (Horrigan 2006). Given the increasing prevalence of search engine usage, which grew almost $70 \%$ between 2002 and 2008 (Fallows 2008), this study explores empirically what search patterns individuals use when seeking out information in search engines on nanotechnology through the following research question:
RQ3: How do nanotechnology online searches compare to other scientific topics?

RQ4: What are the most prominent themes in nanotechnology-related online searches?

Finally, our research identifies what information people do come across when they search for nanotechnology using up to three search terms in a common search engine. Considering the prominence of online information, we utilize a user-oriented perspective to determine where users might encounter content online through keyword searches in a search engine. We then conduct a content analysis using this content in order to answer the following research question:

RQ5: What are the most salient issues surrounding nanotechnology that online audience segments are likely to encounter?

\section{Methods}

This three-part study utilizes three sources of data. First, we examine characteristics of online science media users through two types of data: survey data and behavioral tracking data. The survey data compares the different types of reported media people tend to use for science issues with knowledge of science and nanotechnology and basic demographics. The behavioral data reveals demographic characteristics of people who visit various Web sites. By examining both reported and behavioral data, we aim to capitalize on the strength of both methods and minimize the weaknesses of each. Sole reliance on survey data might miss the actual nature of respondents' behaviors since respondents reveal what they deem most productive to the researchers hosting the survey. If we rely only on behavioral data, we may miss the full picture of individuals' behavior that could vary from the chosen date of data collection. Then we collect primary keyword searching data to determine what the public is searching for online. Finally, we examine what content information people encounter in the online setting.

\section{Survey data}

A randomly sampled general population telephone survey of 1,015 adults was conducted from May to 
July 2007 (AAPOR RR-3: 30.6\%) by the Wisconsin Survey Center. The approximate margin of error was $\pm 3 \%$. In order to minimize systematic non-response, significant time and effort was invested in callbacks and refusal conversions. Variables used include attention to science in various media [internet $(M=$ $3.31, \mathrm{SD}=2.95)$, newspaper $(M=4.57, \mathrm{SD}=2.83)$, television $(M=4.46, \mathrm{SD}=2.84)$, mixed media $(M=3.10, \quad \mathrm{SD}=1.11)]$, knowledge of science $(M=3.18, \mathrm{SD}=1.36)$, knowledge of nanotechnology $(M=3.87, \quad \mathrm{SD}=1.44)$, and demographics, including age $(M=3.12, \quad \mathrm{SD}=1.09)$, education $(M=3.02, \mathrm{SD}=0.94)$, race $(M=0.89, \mathrm{SD}=0.32)$, and gender $(M=0.48, \mathrm{SD}=0.50)$.

Online behavioral data

We use data collected by The Nielsen Company, based on tracking actual Web activity of a panel of users and projecting the data onto the entire online audience in the United States. The panel is recruited using Random Digital Dialing sampling with at least 15 call backs to individuals at varying times and days of the week to ensure a high participation rate. Individuals are required to $\log$ on at the computer, which ensures that activity of members of each household are tracked individually. Our study examines characteristics of unique visitors to prominent science sites and news sites (see Table 1) during the month of March 2009. ${ }^{1}$

Keyword searching data

To analyze how individuals search for nanotechnology, we drew upon the Google AdWords Keyword $\mathrm{Tool}^{2}$ which provides estimates of the volume of keyword searches and related words. We used Google for two reasons. First, recent data show an estimated 5.1 billion Google search queries were conducted in the month of April 2008, which represents $62 \%$ of the total searches for that month (The Nielsen Company 2008). Yahoo, by comparison, is the second most-used search engine, representing just $17.5 \%$ of all searches in that

\footnotetext{
1 The two groups of science sites and news sites were custom groups we created based on data we collected from The Nielsen Company.

${ }^{2}$ Available at: https://adwords.google.com/select/KeywordTool External.
}

Table 1 News and science Web sites used in analysis of Nielsen data

\begin{tabular}{ll}
\hline News & Science \\
\hline BBC News & Discovery Channel \\
CNN & EPA \\
Digg & FDA \\
Google News & How Stuff Works \\
Huffington Post & NASA \\
New York Times & NOAA \\
Reuters & Scientific American \\
USA Today & Sci Fi Channel \\
The Washington Post & Wired \\
Yahoo News & \\
\hline
\end{tabular}

month with approximately 1.4 billion searches (The Nielsen Company 2008). Second, people perceive Google to produce the most relevant search results (Lewandowski 2008). One experiment comparing the use of the unassisted search engine Google to the directory-based Yahoo and a search engine combined with assisted search found that users looked at more documents overall and found information more quickly while using Google (Dennis et al. 2002).

Using the Google tool, we collected the 2008 monthly average of the approximate search volume, which shows the approximate number of search queries in Google for the keyword nanotechnology and other related keywords. Here, we compare nanotechnology with other science keyword searches in the United States and the United Kingdom. We also compare different themes of nanotechnology-related searches in the United States. Of all keywords for which Google presented estimates, we identified nine themes. Two words were selected to represent each theme and compared across the six months investigated.

\section{Content analysis data}

Finally, we turn to keyword-assisted searches in the Google search engine to identify common Web sites people would come across if they were to turn to the Internet for information seeking on nanotechnology. These Web sites comprised the sample for the content analysis component of this study. We tracked keyword searches in Google for two countries: United States (www.google.com) and United Kingdom (www. google.co.uk). We identified the URLs on the first 
results page of a Google search once per week beginning with the week of October 28, 2008 through November 10, 2008 [the first Web page listing the results of an online search is the most used by audiences when revising their searches (Jansen and Spink 2006)]. The search categories consisted of a general nanotechnology search along with 10 categories and 13 subcategories (see Table 1 in Online Appendix) of searches derived from two sources: structured discussions among the general public about nanotechnology (Jones 2008) and public opinion survey data about nanotechnology (Scheufele et al. 2007). The supplementary categories were drawn from these sources to reflect nanotechnology issues the general public deems most relevant.

We selected the most frequently appearing sites in these Google searches to conduct a content analysis of online representations of nanotechnology. We did a count of all basic URLs that appeared in the searches we conducted for nanotechnology, 10 categories, and 13 subcategories. Following this count, we categorized each site from the Google search results into one of five categories: nanotechnology Web site, non-nanotechnology Web site, nanotechnology blog, nonnanotechnology blog, and government Web site. We chose the sites that appeared most frequently within each category to conduct the content analysis (see Table 2). Thus, the sample represents the most frequently appearing Web sites in Google search results within the five categories we defined.

A computer program we developed then provided us with the unique ability to automatically track content in this specified watch list of URL domains. It mines these sites one level deep to capture links on the first page and content from those links within the "body" HTML tags.

We collected data from our watch list of sites on three dates in one month: April 6, 2009, April 25, 2009, and April 29, 2009. The program automatically tracked frequencies of words representing nine themes of nanotechnology that broadly link it to other aspects of society, as performed by Dudo et al. (2009), and added one theme: technology. Three themes were related to applications of nanotechnology: national security, environment, and health. Four were related to policy: technology, research, business, and regulation. The three themes of risk, benefit, and uncertainty represented social implications of nanotechnology. The content was analyzed using six root words per theme (see Table 2 in Online Appendix).

\section{Results}

Online science media users

\section{Differences in types of science media users}

While science in television and newspaper sources primarily attracts older users, science on the Internet attracts a range of ages, with $26.4 \%$ of the 18 34 years old, $28.6 \%$ of the $45-54$ years old, and $25.3 \%$ of the above 55 being likely to utilize Internet sources (see Fig. 1 in Online Appendix). Therefore, a wider range of the population in terms of age is turning to the Internet as a primary source of news for science issues, compared to traditional media.

Among the three different types of media, gender differences were slight. Males (51.9\%) were a little more likely than women to primarily pay attention to science in the Internet (see Fig. 2 in Online Appendix). Women were slightly more likely than men to use other media-newspaper, television, or mixed media-as their primary source of news about science.

Science Internet users are more educated than users of other mediums. More than half $(54.9 \%)$ of Internet users have at least a college degree and all have completed at least a high school degree (see Fig. 3 in Online Appendix). Science newspaper users are also highly educated, with $53.2 \%$ having at least a college degree. Of science television users, $40.9 \%$ had at least a college degree, and $29.6 \%$ had completed some college. Mixed media users had the highest rate of people who have not completed high school (15.0\%) and who have completed just high school $(30.0 \%)$.

As far as race is concerned, the majority of all three types of media users are white, but the group of people who use Internet as their primary source of science information has the largest number of nonwhite users: $16.5 \%$. Among television users, 1 in 10 is non-white. Among newspaper users, just $8 \%$ are non-white. Mixed media users have a slightly larger rate of non-white users at $15.3 \%$ (see Fig. 4 in Online Appendix). Therefore, the populations for science attention in online sources and the mixed media sources, which include online outlets, are more diverse in terms of race than other media sources.

Those who use the Internet as a primary source of news on science have higher levels of knowledge on 
Table 2 Web sites used in content analysis

\begin{tabular}{|c|c|}
\hline Web site type & Web sites \\
\hline $\begin{array}{l}\text { Nanotechnology } \\
\text { Web site }\end{array}$ & $\begin{array}{l}\text { www.nanowerk.com } \\
\text { www.nanotech-now.com } \\
\text { www.crnano.org } \\
\text { www.azonano.com } \\
\text { www.foresight.org }\end{array}$ \\
\hline $\begin{array}{l}\text { Non-nanotechnology } \\
\text { Web site }\end{array}$ & $\begin{array}{l}\text { www.sciencedaily.com } \\
\text { www.nature.com } \\
\text { (and www.nature.com/nnano) }\end{array}$ \\
\hline Nanotechnology blog & $\begin{array}{l}\text { www.wolbring.wordpress.com } \\
\text { www.crnano.typepad.com } \\
\text { www.nanomat.blogspot.com }\end{array}$ \\
\hline $\begin{array}{l}\text { Non-nanotechnology } \\
\text { blog }\end{array}$ & $\begin{array}{l}\text { www.timprosserfuturing. } \\
\text { wordpress.com } \\
\text { www.bioethicsdiscussion. } \\
\text { blogspot.com }\end{array}$ \\
\hline Government Web site & $\begin{array}{l}\text { www.epa.gov } \\
\text { www.nano.gov } \\
\text { www.cordis.europa.eu } \\
\text { www.nano.cancer.gov } \\
\text { www.fda.gov (and } \\
\text { www.fda.gov/nanotechnology) }\end{array}$ \\
\hline
\end{tabular}

general science issues than those who use other sources (see Fig. 5 in Online Appendix). Nearly 3 in 10 Internet users could answer all five questions about science knowledge correctly, while only $20 \%$ of newspaper users and $15 \%$ of television users could. Furthermore, less than $1 \%$ of Internet users could not answer any science knowledge questions correctly, but $5 \%$ of television users and $2 \%$ of newspaper users could not answer any science knowledge question correctly.

This trend becomes even more pronounced on the specialized science topic of nanotechnology, for which Internet users were most likely to answer knowledge questions correctly (see Fig. 6 in Online Appendix). Internet users were about $10 \%$ more likely to answer more than three knowledge questions about nanotechnology correctly. Of people who primarily use Internet as their main source of news, $73 \%$ answered four or more questions correctly. Among people who primarily use the newspaper or television, $62 \%$ answered four or more questions about nanotechnology correctly. However, Internet and newspaper users were about equally as likely- about $11 \%$ - to answer all six knowledge questions correctly.

In sum, our survey data show that those who pay attention to science primarily in Internet are diverse as far as age is concerned, with one-fourth being between 18 and 34 years old, knowledgeable about science and nanotechnology, highly educated, male, and slightly more diverse racially than other users of other media.

\section{Differences in users of science and general news Web sites}

The tracking data of users of science and news Web sites pertains to online users of both science and general news sites, which allows us to determine if science users online are different from general users. Some of the online science news users' profile information revealed in the survey data was also applicable to users of general news media online. While science sites attracted more male and nonwhite users than news sites, both types of sites attracted young users and news sites attracted those with a higher level of education (see Table 3 in Online Appendix for the full list of categories).

There were only slight differences in the ages of users of science sites and general news sites. The science sites appear to draw younger users than news sites, but not by much. In both types of sites, the youngest group of individuals aged 18-34 made up $18 \%$ of all users. Science sites had slightly more people between the ages of 35 and 49 (37.0\%) than news sites $(36.4 \%)$ and slightly more between the ages of 50 and $64(35.8 \%)$ than news sites (29.8\%). News sites had more people over the age of $65(9.3 \%)$ than science sites, which had $7.7 \%$.

Both science and general news sites had more male users than female. Science sites had a higher percentage of male users $(60.2 \%)$ than general news sites had (54.4\%). News sites had a higher percentage of female users $(45.6 \%)$ than science sites had $(39.8 \%)$.

Interestingly, general news sites had slightly more people who had obtained a higher level of education than science sites had. In news sites, $20.8 \%$ of users had obtained a post-graduate degree and $37.1 \%$ had obtained a college degree. Only $8.6 \%$ of users of news sites had not completed high school. In science sites, $18.6 \%$ of users had a post-graduate degree, 
while $39.5 \%$ had completed a college degree. More than 1 in 10 users (13.4\%) had only completed up to some high school.

News sites had more white users $(89.0 \%)$ than science sites had $(76.8 \%)$. Together with the survey data presented earlier, it seems that online sources of information, specifically around science Web site users, draw a more diverse range of ethnic backgrounds.

Regional data show that science sites drew a larger user population from people in the Western region of the United States (32.7\%), while news sites only drew $23.8 \%$ of their readership from the West.

In sum and according to the survey data, people who are educated, male, and knowledgeable about science and nanotechnology and of different age groups reported the Internet was their primary source of information for science news. According to the Internet audience behavioral data, science Web site users tend to draw more middle-aged and less educated people than general news sites do. However, science sites attract more non-white and male users than general news sites do.

Searching for nanotechnology online

Not surprisingly, average numbers of keyword searches for nanotechnology in 2008 in the United States reveal that nanotechnology was searched much less than other (often older) science-related issues (see Fig. 1). In the United States, it garnered fewer searches than biotechnology, climate change, and stem cell research. Nanotechnology, however, was searched more than biofuels. In the United Kingdom, on the other hand, nanotechnology was searched more than was stem cell research and about the same amount of times as biofuels. It was still searched less than climate change and biotechnology.

The nanobots theme was the highest searched theme with an average of 9,180 searches per month in 2008 (see Fig. 2). Health was also widely searched with an average of 6,230 searches for a variety of searches around the words "nanotechnology" and "medicine," as well as "nanotechnology cancer." Other popular themes were definition, applications, research and science, with each receiving an average of more than 4,000 searches per month in 2008. Economy was searched an average of 3,750 times per month in 2008, while future was searched an average of 2,990 times per month in 2008. Government and regulation, information, and biology were the leastsearched themes.

Overall, this data show nanotechnology is searched less than other scientific topics. Given the topical focus of nanotechnology-related keyword searches around future, health, and applications, searchers seem to be interested in where the technology is going and what the application of the technology can provide. People are turning to the Internet searching for definitions about nanotechnology, but they are not

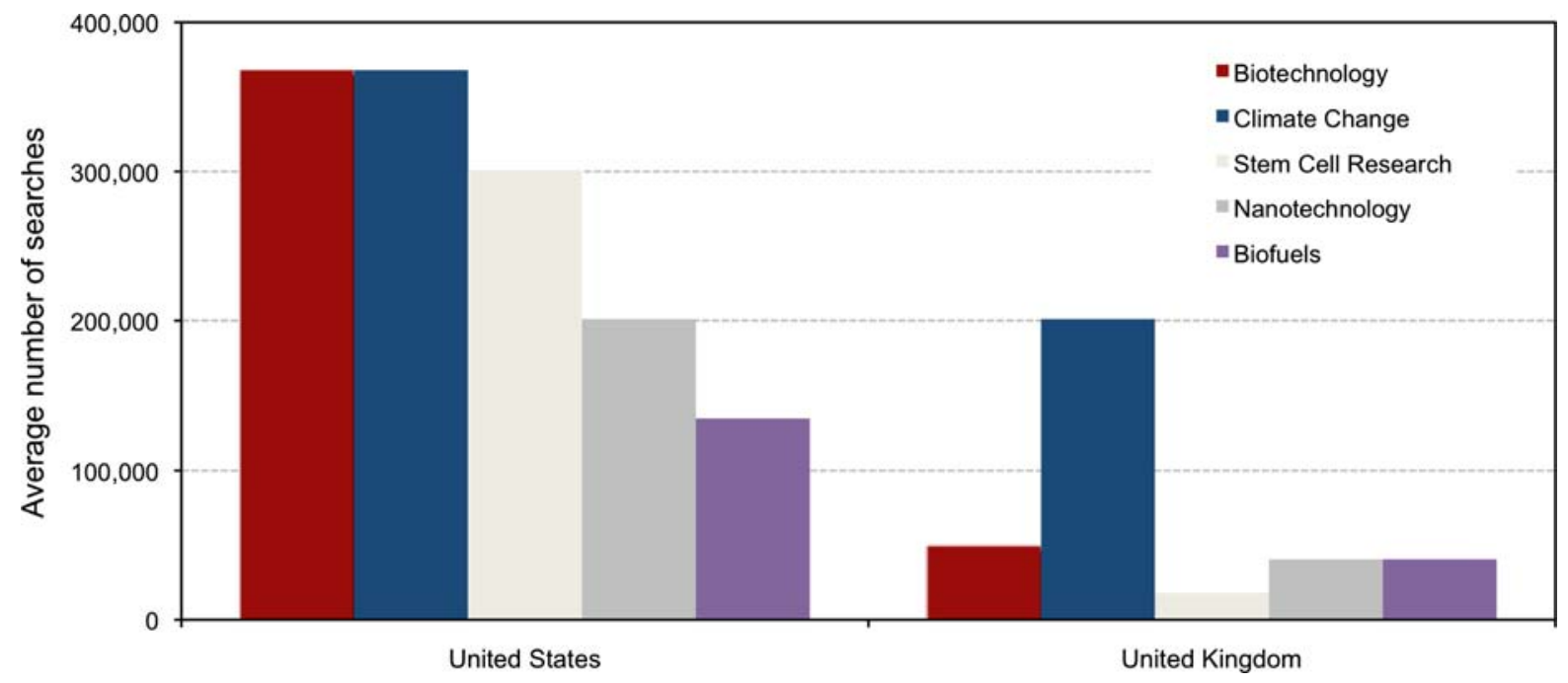

Fig. 1 Average number of science topic searches in 2008 


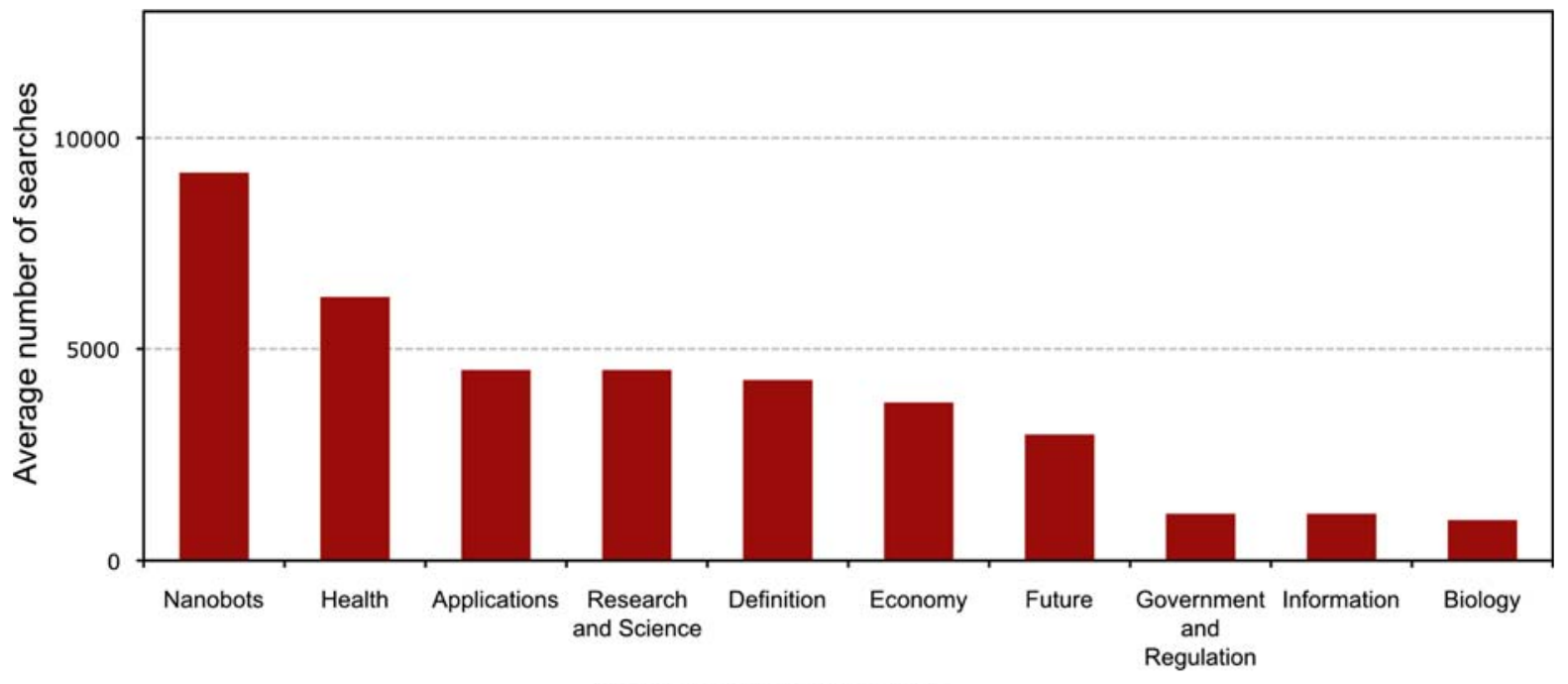

Keyword Search Themes

Fig. 2 Average number of nanotechnology-related keyword searches by topic in 2008

seeking out traditional online sources of information, such as news or blogs. Furthermore, although policy and regulatory aspects of nanotechnology are on the radar of Internet searchers, they are not highly searched themes within nanotechnology searches.

Mapping online content of nanotechnology

Overall, the dimension of health dominated the Web content, with an average of 15.4 mentions per link (see Fig. 3). Technology, research, and business were the next most-mentioned dimensions in the Web content overall, with 8.4, 8.0, and 7.0 mentions per link, respectively. The environment received an average of 5.2 mentions per link, while national security received an average of 4.1 mentions per link. Regulations were mentioned an average of 4.7 times per link. Social implications were the least mentioned of all of the themes. Risk was mentioned 3.3 times per link, while benefit was only mentioned 1.5 times. Uncertainty, however, was mentioned less than 0.5 times per link.

Interesting differences in nano content appeared between the nano-specific and non-nano-specific Web sites. Application themes, such as health, environment, and national security, dominated nonnanotechnology sites, while policy dimensions dominated nanotechnology sites (see Fig. 4). Health was mentioned an average of 19.1 times per link in non- nanotechnology sites, but only 1.5 times per link in nanotechnology sites. Furthermore, environment and national security were mentioned 14.2 and 9.2 times per link in non-nanotechnology sites, but only 1.1 and 0.7 times per link in nanotechnology sites. In nanotechnology sites, business and technology were the most-mentioned dimension with 6.6 and 4.9 mentions per link, respectively. Non-nanotechnology sites were more likely to mention risk and nanotechnology sites were more likely to mention benefit. Both nanotechnology and non-nanotechnology sites rarely mentioned uncertainty at all, with both mentioning it about 0.1 times per link.

In nanotechnology blogs, the environment was mentioned the most with 21.0 mentions per link (see Fig. 5). Technology and national security were also widely mentioned, with 17.0 and 16.7 mentions per link, respectively. In non-nanotechnology blogs, health was the most-mentioned dimension, with 29.0 mentions per link. Technology and business were the next most mentioned, with 10.9 and 10.3 mentions, respectively. Both nanotechnology and non-nanotechnology blogs were more likely to mention risk than benefit. Both types of blogs still rarely mentioned uncertainty with less than 1.0 mention per link.

Business was the most-mentioned dimension in government sites with 8.7 mentions per link (see Fig. 6). Health was the next most dominant theme in government sites, with 5.0 mentions per link. 


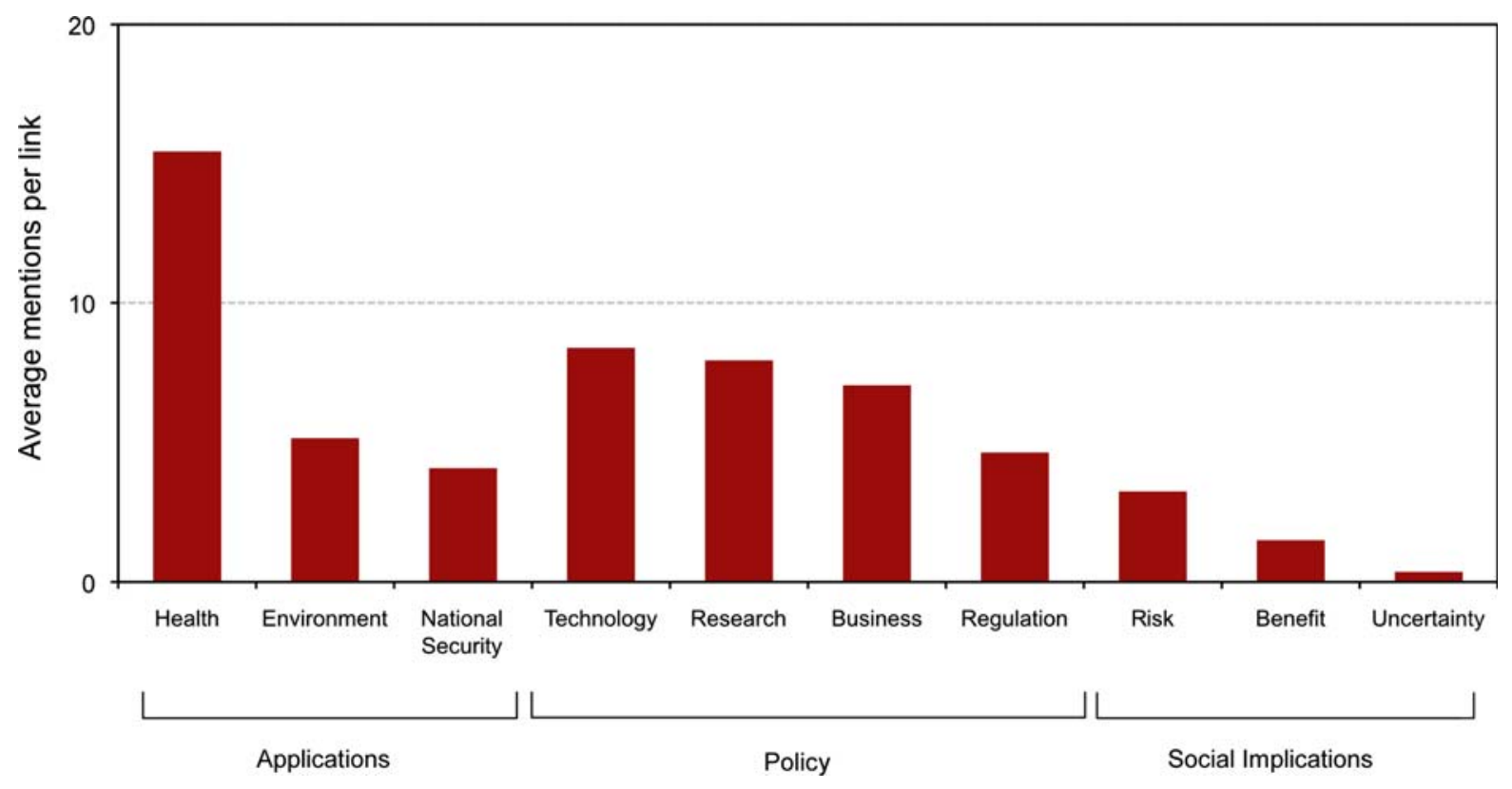

Fig. 3 Dimensions in Web content

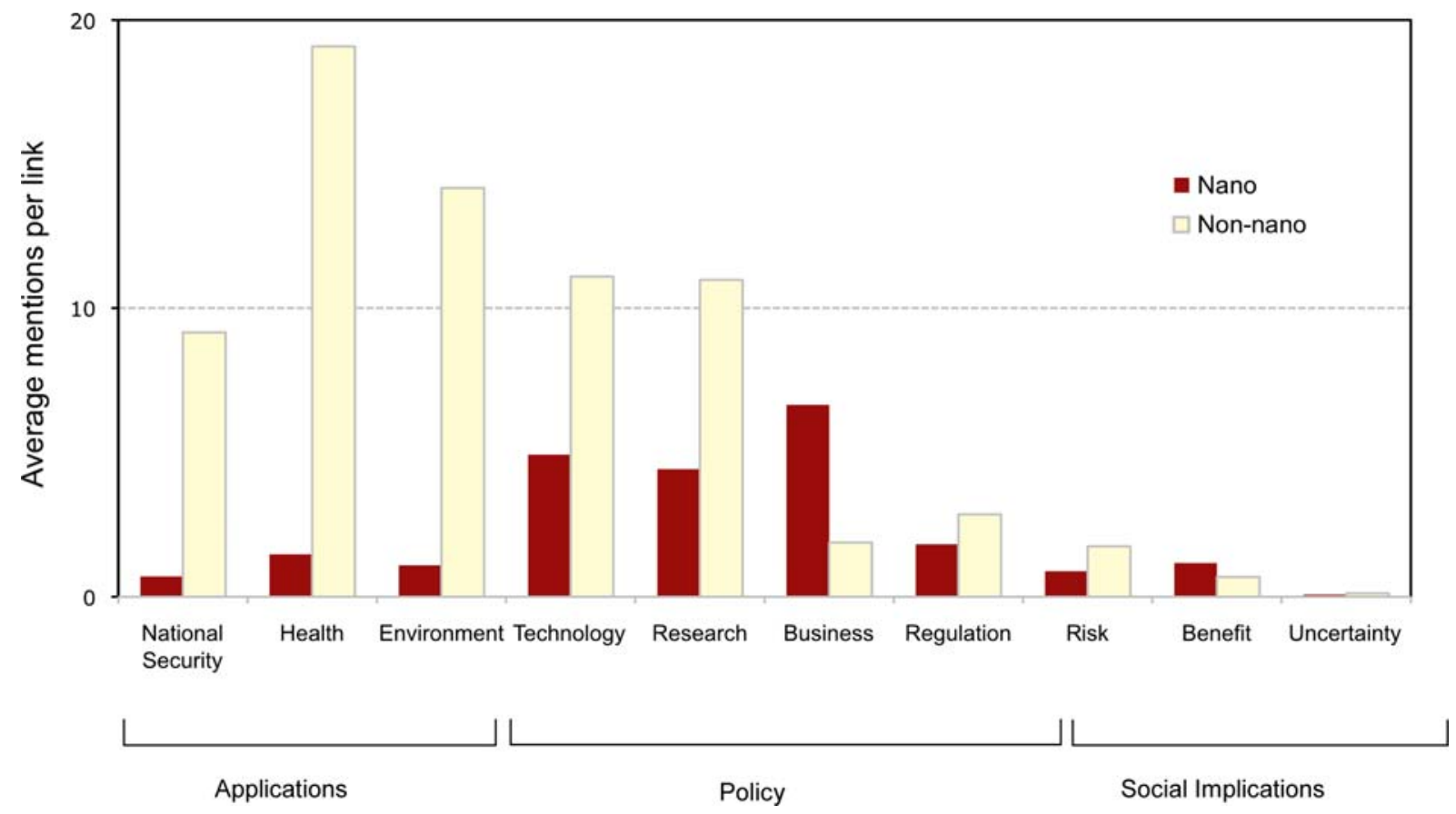

Fig. 4 Dimensions in Web content in nano vs. non-nano sites

Regulations and research were the only other application or policy dimensions that received more than 1.0 mention per link. Of the social implications, government sites mentioned risk 2.0 times, and benefit only 0.7 times. Uncertainty was mentioned only 0.5 times.

In sum, and across all types of sites, a couple of trends emerged. All sites had a prominent focus on 


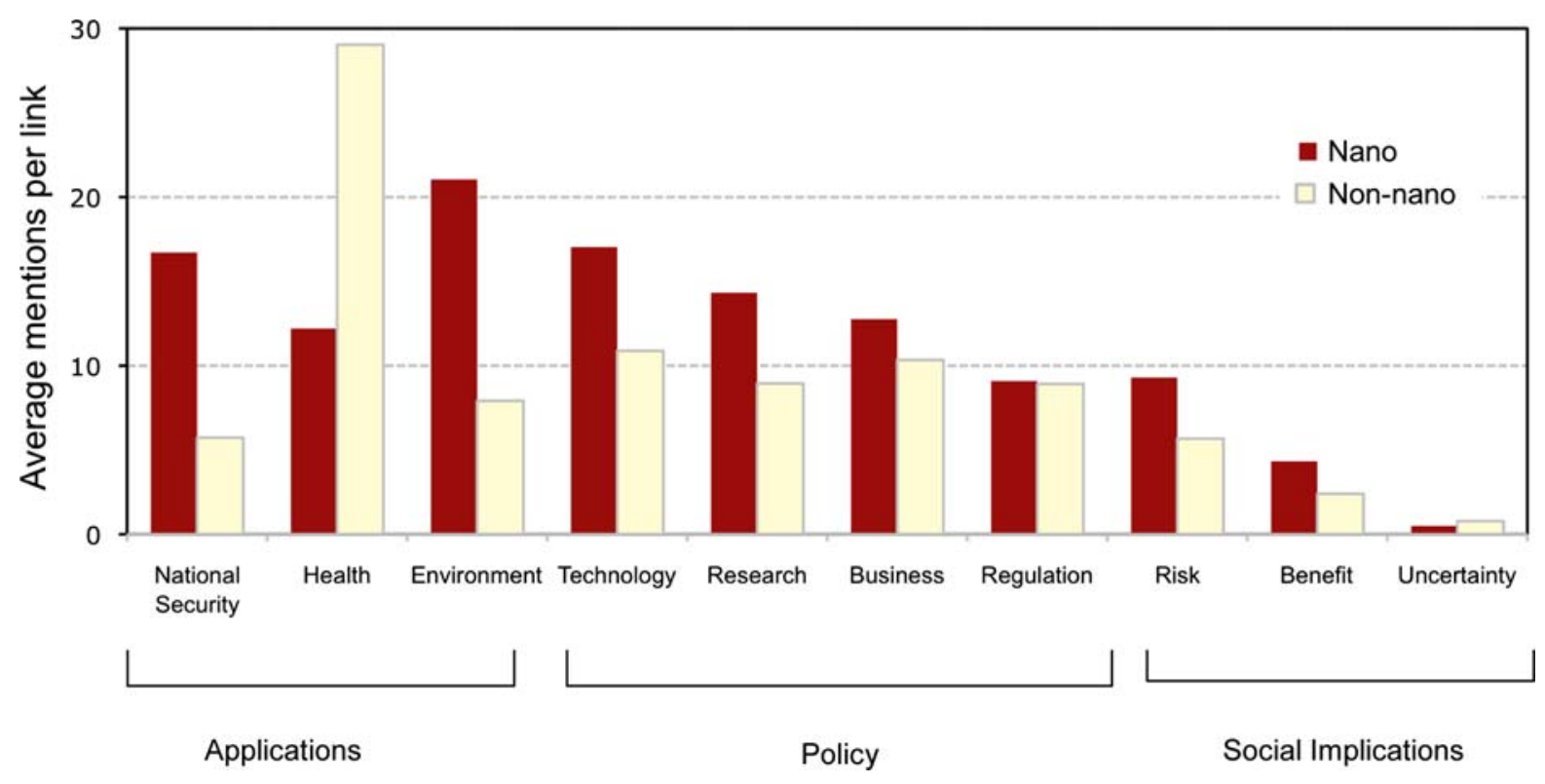

Fig. 5 Dimensions in Web content in nano vs. non-nano blogs

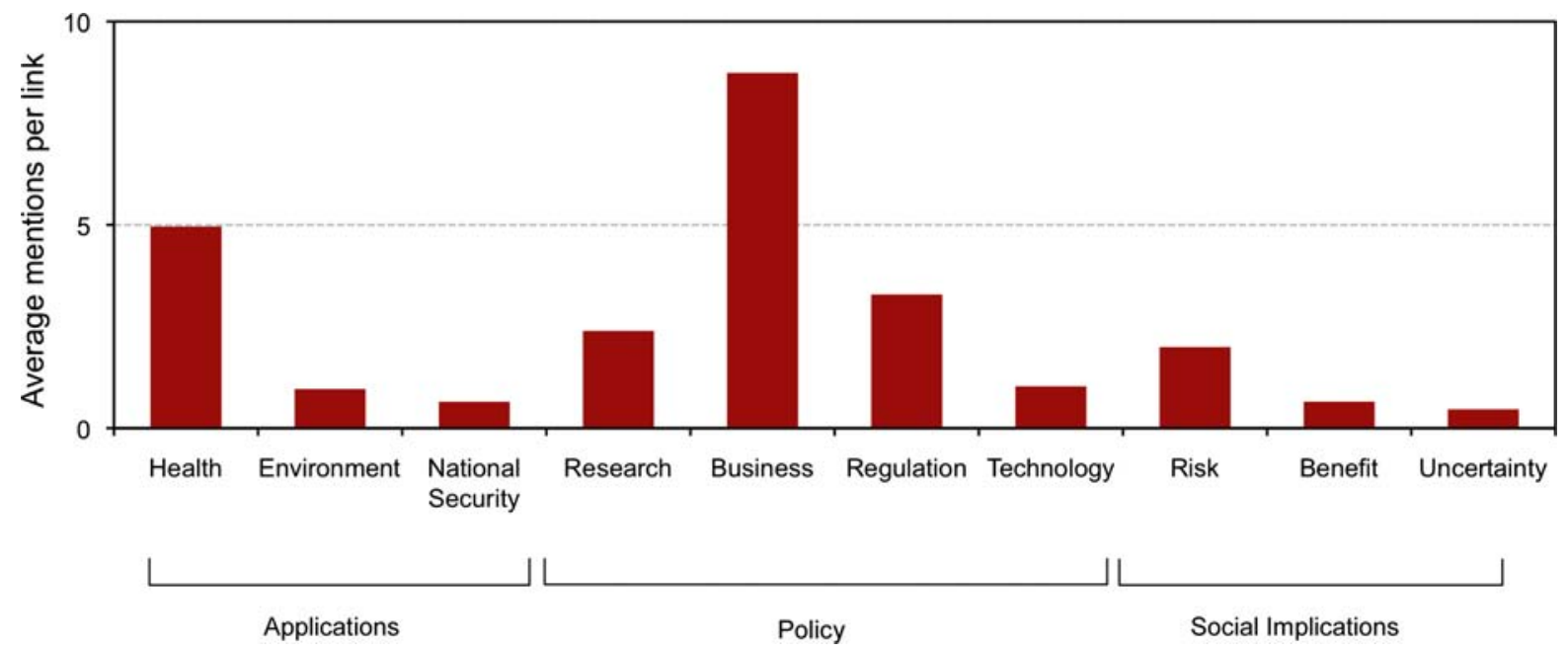

Fig. 6 Dimensions in Web content in government sites

the health dimension of nanotechnology. Of the social implications dimensions represented in all sites, risk was more prominent than benefit and mentions of uncertainty were low. Nanotechnology sites focused more on applications of nanotechnology, while non-nanotechnology sites focused more on policy aspects. Nanotechnology blogs focused more on applications like environment and national security, while non-nanotechnology blogs focused more on health and business. Government sites focused on health and business.

\section{Conclusion}

This study provided an empirical overview of who online science users are, what kinds of nanotechnology information they search for online, and what 
information they are likely to encounter in online sources of information about nanotechnology.

Our demographic data provide a unique breadth given its double-barreled approach. By using both behavioral and self-reported data, we are able to take advantage of the strengths of both sources. The survey data reveal the self-reported usage of different media for science information while the tracking behavioral data reveal the actual usage of sites by different individuals. Some of the characteristics we identify in online users of science in the survey data also reveal themselves in online users of general news sites. Previous research has shown these characteristics among online users in general or of political information, and our data also reveal these characteristics among science users. We found that those who primarily use the Internet for science information are diverse in age, educated, male, more racially diverse than users of other media, and knowledgeable about science in general and nanotechnology in particular. Yet, the behavioral data that examine demographic data of news and science Web site users show that not all of those characteristics are specific to science sites. News site users are also diverse in age but are slightly more educated, and science site users tend to be more male.

While there may be significant barriers to Internet access for certain demographic groups, such as those above age 65 and those with lower education and income levels (Rainie 2010), our study indicates that once members of these demographic groups do gain access to the Internet, the potential for the Internet to close socio-economic gaps and racial divides is high. Internet exposure closes knowledge gaps among individuals of differing education levels on the issue of nanotechnology (Corley and Scheufele, 2010). Furthermore, usage of traditional media, such as television or newspapers, has been identified as a key variable when examining familiarity with or risk perception of nanotechnology (Satterfield et al. 2009). Our findings reveal online media usage is also important characteristic in relation to knowledge of science and nanotechnology. Considering the connection between familiarity with nanotechnology and higher levels of perceived benefit of the technology (Satterfield et al. 2009), the connection we find between online media usage and knowledge indicates there may also be a connection between Internet usage and risk perceptions of nanotechnology among the public.
Our study shows general searching for nanotechnology online is still low relative to other science issues, with searches for nanotechnology centering around its applications. The content analysis revealed that health dominates online content related to nanotechnology while uncertainty-related themes are generally absent. Specific genres of sites reveal other content differences. Mainly, nanotechnology sites are more focused on policy dimensions, while non-nanotechnology sites are more focused on applications. Nanotechnology blogs, on the other hand, are more focused on applications than policy dimensions. Government sites appear to be heavily focused on the business and health dimensions.

What the public shows interest in through keyword searching also appears to be prominent in content of nanotechnology online. Health and general interest in applications were predominant in both. Yet, other applications, such as environment and national security, were absent in the keyword searches and lower in the content analysis of all sites put together. The predominance of health-related information in both online content and in keyword searches reflects the importance of online information sources for researchers in nanotoxicology who want to communicate with the public.

The keyword search data also reveal the public is interested in where the technology is going, which is a type of neutral uncertainty. Yet the content analysis, more focused on a negative uncertainty analyzing words like controversy, unclear, and inconclusive, revealed very little focus on uncertainty. It would be worthwhile to examine more neutral or positive tones of uncertainty in the online content in the future.

Recent models of public engagement, such as consensus conferences-or discussion forums, emphasize the importance of alternative ways for the public to seek out information about emerging technologies (Guston 1999). What these models have not yet addressed is the importance of online sources of information as a means for engaging the public. The presence of science communication consumers online is of increasing importance for scientists, policymakers, and more generally those who fund nanotechnology and are interested in engaging with its publics. Overall, the trend toward online sources for science-related information and the depth of public interest in applications of nanotechnology reveals the important role the Internet is playing in 
the public's awareness and understanding of nanotechnology. Future research about communication and public understanding of the technology will undoubtedly focus on online sources. The challenge for researchers will be to deal with the massive nature of online content and to understand which kinds of content attract different users, with what effect in public attitudes and perceptions.

Acknowledgments This material is based on work supported by National Science Foundation grants (Grants No. DMR 0832760, DMR 0425880, SES-0809470, and SES-0531194). Any opinions, findings, and conclusions or recommendations expressed in this material are those of the authors and do not necessarily reflect the views of the National Science Foundation. The authors would like to thank Jon Stewart at The Nielsen Company for his help in accessing and working with the Nielsen data.

\section{References}

Corley EA, Scheufele DA (2010) Outreach gone wrong? When we talk nano to the public, we are leaving behind key audiences. The Sci 24(1):22

Dennis S, Bruza P, McArthur R (2002) Web searching: a process-oriented experimental study of three interactive search paradigms. J Am Soc Inform Sci Technol 53(2): $120-133$

Dudo A, Dunwoody S, Scheufele DA (2009) The emergence of nano news: Tracking thematic trends and changes in media coverage of nanotechnology. Paper presented at the Association for Education in Journalism \& Mass Communication

Fallows D (2008) Almost half of all Internet users now use search engines on a typical day. Pew Internet \& American Life Project. Retrieved from http://www.pewinternet. org/ /media//Files/Reports/2008/PIP_Search_Aug08.pdf. pdf

Guston DH (1999) Evaluating the first U.S. consensus conference: the impact of the citizens' panel on telecommunications and the future of democracy. Sci Technol Hum Values 24(4):451-482

Horrigan JB (2006) The Internet as a resource for news and information about science. Pew Internet \& American Life Project. Retrieved from http://www.pewinternet.org/Reports/ 2006/The-Internet-as-a-Resource-for-News-and-Informationabout-Science.aspx

Horrigan JB (2009) Wireless Internet use. Pew Internet \& American Life Project. Retrieved from http://www.pew internet.org/Reports/2009/12-Wireless-Internet-Use.aspx
Jansen BJ, Spink A (2006) How we are searching the World Wide Web? A comparison of nine search engine transaction logs. Inform Process Manag 42:248-263

Jones R (2008) When it pays to ask the public [Editorial Material]. Nat Nanotechnol 3(10):578-579

Kelland K (2009) Gold nanotech breath test may show lung cancer early. Reuters. Retrieved September 19, 2009, from http://www.reuters.com/article/scienceNews/idUST RE57T1MF20090830

Lenhart A, Fox S (2009) 11\% of online adults use Twitter or update their status online: Twitter users are mobile, less tethered by technology. Pew Internet Project Data Memo. Retrieved from http://www.pewinternet.org/ /media// Files/Reports/2009/PIP\%20Twitter\%20Memo\%20FINAL. pdf

Lewandowski D (2008) The retrieval effectiveness of web search engines: considering results descriptions [Article]. J Doc 64(6):915-937

Lyn TE (2009). Deaths, lung damage linked to nanoparticles in China. Reuters. Retrieved September 19, 2009, from http:// www.reuters.com/article/latestCrisis/idUSN19481304

National Science Board (2004) Report: excerpts from science and engineering indicators 2004. Sci Commun 26:219-222

Peng G, Tisch U, Adams O, Hakim M, Shehada N, Broza YY et al (2009) Diagnosing lung cancer in exhaled breath using gold nanoparticles. Nat Nanotechnol (advance online publication). doi:10.1038/nnano.2009.235

Pew Research Center (2008) Audience segments in a changing news environment: key news audiences now blend online and traditional sources. Pew Research Center Biennial News Consumption Survey. Retrieved from http://peoplepress.org/reports/pdf/444.pdf

Pew Research Center (2009) Newspapers face a challenging calculus: online growth, but print losses are bigger. Pew Research Center for the People \& the Press. Retrieved from http://pewresearch.org/pubs/1133/decline-print-news papers-increased-online-news

Rainie L (2010) Internet, broadband, and cell phone statistics. Pew Internet \& American Life Project

Satterfield T, Kandlikar M, Beaudrie CEH, Conti J, Harthorn $\mathrm{BH}$ (2009) Anticipating the perceived risk of nanotechnologies. Nat Nanotechnol 4(11):752-758

Scheufele DA, Corley EA, Dunwoody S, Shih TJ, Hillback E, Guston DH (2007) Scientists worry about some risks more than the public [Editorial Material]. Nat Nanotechnol 2(12):732-734

Song Y, Li X, Du X (2009) Exposure to nanoparticles is related to pleural effusion, pulmonary fibrosis and granuloma. Eur Respir J 34(3):559-567

The Nielsen Company (2008) Nielsen online announces April U.S. search share rankings. Retrieved 3/29, 2009, from http://www.nielsen-netratings.com/pr/pr_080519.pdf 